\title{
Child injury: An emerging health burden in low-income countries
}

\author{
Saidur Rahman Mashreky
}

Director, Centre for Injury Prevention and Research Bangladesh (CIPRB), Dhaka, Bangladesh.

Globally, injuries are a major public health problem: more than 5.8 million people die every year due to injuries. ${ }^{1}$ For every person who dies of injuries, several thousand injured people survive, but many of them are left with permanent disabilities. ${ }^{2}$ Due to the socio-economic changes, and demographic and epidemiological transitions in a majority of the low and middle-income countries, the pattern of mortality and morbidity is changing and the trends of injuries and non-communicable diseases are also rising. Throughout the world, injury and violence is a major killer of the children and is responsible for about 950,000 deaths every year. ${ }^{3}$ More than $95 \%$ of them occur in low and middle-income countries. ${ }^{3}$ Drowning is the most common cause of unintentional injuries and death among children in Asian and many other low-income countries; other causes include: road traffic injury, fall, burn, and injuries caused by animals. ${ }^{4}$

Children who live in poverty are the most vulnerable and experience the greatest burden of injury. Even then, in many of the developing countries, injury is an unrecognised public health problem. Historically, injuries have been viewed as a neglected public health issue. ${ }^{5}$ People view injury is an 'accident' or random event and as something that is not preventable. However public health professionals have recognized that injuries are preventable. ${ }^{6}$

The approach to injury prevention involves some key epidemiological approaches like determining the magnitude, scope, and characteristics of the problem; identifying the factors that increase the risk of injury or disability; determining the factors which are potentially modifiable; and identifying the measures to be taken to prevent the problems. Finally implementing the most promising interventions in a culturally-relevant setting with a costeffective way is a real challenge for public health professionals. $^{2}$

Because of a lack, or poor provision of death and illness registration, most of the low and middle-income countries have very limited information about causes of death and illness, and consequently have become less aware about causes of illness and deaths. A national injury survey can help them to understand the burden of injuries and design appropriate preventive strategies in those countries. ${ }^{7}$
In Bangladesh, $38 \%$ children of 1-17 years die due to injuries, which make it the leading cause of death, as revealed by the Bangladesh Health and Injury Survey (BHIS). ${ }^{8}$ It was estimated that over 30,000 children aged 0-17 years die from injuries each year, more than half of which are the result of drowning. Lack of awareness, inadequate supervision, lack of life saving skill, hazardous environment and rural residence are the major determinants of childhood injuries in Bangladesh. ${ }^{7}$ Similar scenarios have also been found in other low-income countries, including ones in the Asia region. ${ }^{4,5}$ Injury was found as the $5^{\text {th }}$ leading cause of death in 1-59 month-old children in India. ${ }^{9}$ Injury-related-deaths account for nearly $20 \%$ of all deaths in children in Vietnam and drowning was found to be the most common cause of injury. ${ }^{10}$

Considering the magnitude and risk factors, the Centre for Injury Prevention and Research, Bangladesh designed a comprehensive child injury prevention package named the 'Prevention of Child Injury through Social intervention and Education (PRECISE)' and implemented it for five years (2006-2010) in selected areas of Bangladesh. ${ }^{11}$ Both active and passive approaches were adopted in this prevention program. Along with behavioral change communication, life skill training, such as swimming and first aid, was provided to the children. Low cost, locally available, and culturally appropriate technologies were utilized in this prevention program. ${ }^{11}$ After five years of implementation of the program, and covering about 800,000 members of the population, it was found to be feasible, cost-effective, and acceptable by the people. ${ }^{11,12}$ It was also found to be effective in reducing injury-related mortalities. Compared to the baseline, deaths from injuries were reduced by about $40 \%$ and injury related hospitalization was also reduced by about $46 \%$ among $1-4$ year-old children in the intervention area. ${ }^{11,12}$ The experiences in Bangladesh can be utilized in countries with similar socio-economic and cultural settings.

Injury is preventable even in the resource poor and low income countries. Now, the time has come to develop effective country specific injury prevention strategies that will help to combat the effect of injuries on the health of the world's population, especially children.

Correspondence: Dr. Saidur Rahman Mashreky, Director, Centre for Injury Prevention and Research Bangladesh (CIPRB), House B-162; Road 23, New DOHS, Mohakhali, Dhaka-1206, Bangladesh. E-mail: mashreky@ciprb.org. Web: www.ciprb.org. 


\section{References}

1. WHO. Injuries and violence: the facts. Geneva: World Health Organization, 2010.

2. Krug EG, Sharma GK, Lozano R The Global Burden of Injuries. Am $J$ Public Health 2000;90:523-6.

3. WHO. World report on child injury prevention. Geneva: World Health Organization, 2008.

4. Linnan M, Giersing M, Cox R, Linnan H, Williams MK, Voumard C, Hatfield R. Child mortality andiInjury in Asia: An overview. Innocenti Working Paper 2007-04, Special series on Child Injury No. 1. Florence: UNICEF, 2007.

5. Bartlett SN. The problem of children's injuries in low-income countries: a review. Health Policy Plann 2002;17:1-13.

6. Haddon W. The changing approach to the epidemiology, prevention, and amelioration of trauma: the transition to approaches etiologically rather than descriptively based. Am J Public Health 1968;58:1431-8.

7. Khademi H, Etemadi A, Kamangar F, Nouraie M, Shakeri R, Abaie B, et al. Verbal Autopsy:
Reliability and validity estimates for causes of death in the Golestan Cohort Study in Iran. PLoS ONE2010;5:e11183.

8. DGHS. Bangladesh Health and Injury Survey. Child Report 2005. Dhaka: Directorate General of Health Services, 2005.

9. Bassani DG, Kumar R, Awasthi S, Morris SK, Paul VK, Shet A, et al. Causes of neonatal and child mortality in India: a nationally representative mortality survey. Lancet 2010;376:1853-60.

10. Tran TNL, Luong MA, Khieu TQT. Situation of child injuries in Vietnam and interventions. Inj Prev 2012;18:A16-A17.

11. Rahman F, Bose S, Linnan M, Rahman A, Mashreky S, Haaland B, Finkelstein E. Costeffectiveness of an injury and drowning prevention program in Bangladesh. Pediatrics 2012;130:i1621-8.

12. CIPRB. Evaluation of PRECISE: a comprehensive child injury prevention program in Bangladesh, The First Three Years 2006-2008. Dhaka: Centre for Injury Prevention and Research Bangladesh, 2009. 